\title{
Advancing engagement and capacity for rural cancer control: a mixed-methods case study of a Community-Academic Advisory Board in the Appalachia region of Southwest Virginia
}

Jamie M. Zoellner ${ }^{1 *}$ (D) Kathleen J. Porter ${ }^{1} \mathbb{D}$, Donna-Jean P. Brock ${ }^{1}$, Emma Mc Kim Mitchell ${ }^{\mathbb{D}}$, Howard Chapman Jr ${ }^{3}$, Deborah Clarkston ${ }^{4}$, Wendy Cohn ${ }^{5}$ (D) Lindsay Hauser ${ }^{6}$, Dianne W. Morris ${ }^{7}$, Sarah Y. Ramey ${ }^{8}$, Brenna Robinson ${ }^{6}$, Scott Schriefer ${ }^{9}$, Noelle Voges ${ }^{10}$ and Kara P. Wiseman ${ }^{5}$ (D)

\begin{abstract}
Background: The objectives are to: 1) describe engagement processes used to prioritize and address regional comprehensive cancer control needs among a Community-Academic Advisory Board (CAB) in the medicallyunderserved, rural Appalachian region, and 2) detail longitudinal $C A B$ evaluation findings.
\end{abstract}

Methods: This three-year case study (2017-2020) used a convergent parallel, mixed-methods design. The approach was guided by community-based participatory research (CBPR) principles, the Comprehensive Participatory Planning and Evaluation process, and Nine Habits of Successful Comprehensive Cancer Control Coalitions. Meeting artifacts were tracked and evaluated. CAB members completed quantitative surveys at three time points and semi-structured interviews at two time points. Quantitative data were analyzed using analysis of variance tests. Interviews were audio recorded, transcribed, and analyzed via an inductive-deductive process.

Results: Through 13 meetings, Prevention and Early Detection Action Teams created causal models and prioritized four cancer control needs: human papillomavirus vaccination, tobacco control, colorectal cancer screening, and lung cancer screening. These sub-groups also began advancing into planning and intervention proposal development phases. As rated by 49 involved CAB members, all habits significantly improved from Time 1 to Time 2 (i.e., communication, priority work plans, roles/accountability, shared decision making, value-added collaboration, empowered leadership, diversified funding, trust, satisfaction; all $p<.05)$, and most remained significantly higher at Time 3. CAB members also identified specific challenges (e.g., fully utilizing member expertise), strengths (e.g., diverse membership), and recommendations across habits.

\footnotetext{
* Correspondence: jz9a@virginia.edu

'Department of Public Health Sciences, School of Medicine, University of Virginia, 16 E. Main St, Christiansburg, VA 24073, USA

Full list of author information is available at the end of the article
}

C C The Author(s). 2021 Open Access This article is licensed under a Creative Commons Attribution 4.0 International License, which permits use, sharing, adaptation, distribution and reproduction in any medium or format, as long as you give appropriate credit to the original author(s) and the source, provide a link to the Creative Commons licence, and indicate if changes were made. The images or other third party material in this article are included in the article's Creative Commons licence, unless indicated otherwise in a credit line to the material. If material is not included in the article's Creative Commons licence and your intended use is not permitted by statutory regulation or exceeds the permitted use, you will need to obtain permission directly from the copyright holder. To view a copy of this licence, visit http://creativecommons.org/licenses/by/4.0/ The Creative Commons Public Domain Dedication waiver (http://creativecommons.org/publicdomain/zero/1.0/) applies to the data made available in this article, unless otherwise stated in a credit line to the data. 
Conclusion: This project's equity-based CBPR approach used a CPPE process in conjunction with internal evaluation of cancer coalition best practices to advance CAB efforts to address cancer disparities in rural Appalachia. This approach encouraged CAB buy-in and identified key strengths, weaknesses, and opportunities that will lay the foundation for continued involvement in cancer control projects. These engagement processes may serve as a template for similar coalitions in rural, underserved areas.

\section{Plain English summary}

There has been notable progress among state and local cancer coalitions in developing and implementing comprehesive cancer control plans. Yet, gaps exist in rural communities and cancer remains a leading cause of death in rural populations. This paper reports on how the involvement of a Community-Academic Advisory Board (CAB) helped to prioritize cancer control and research needs in the medically-underserved, rural Appalachian region. CAB members were asked to participate in meetings and to share their experiences through surveys and interviews. Through this three-year process, four cancer control needs were prioritized: human papillomavirus vaccination, tobacco control, colorectal cancer screening, and lung cancer screening. Also, over the course of the project, CAB members' experiences improved, including: communication, priority work plans, roles/accountability, shared decision making, value-added collaboration, empowered leadership, diversified funding, trust, satisfaction. During the interviews, CAB members identified specific challenges, strengths, and recommendations. The opportunities and barriers at building and sustaining capacity as well as advancing a communitydriven research agenda to address cancer disparities in rural Appalachia is discussed.

Keywords: Cancer, Community-based participatory research, Community capacity, Mixed-methods, Medically underserved area, Healthcare coalitions

\section{Introduction}

Comprehensive cancer control (CCC) efforts refer to an integrated partnership approach that fosters collaboration among multiple organizations to prioritize, develop, and implement plans that address cancer burden across the cancer control continuum. As such, demand for patient and stakeholder engagement in research has been emphasized across federally funded calls for proposals and cancer control initiatives [1,2]. Extensive literature highlights both the importance and complexity of building community partnerships and sustaining research capacity $[3,4]$. However, despite ongoing recommendations to engage stakeholders in CCC research efforts, the extent of stakeholder involvement through core research phases varies greatly. Historically, there have been relatively few reports of community stakeholders setting research priorities and generating hypotheses [5, 6]. Practical methods are also needed to advance the role of stakeholders along the engagement spectrum (e.g., inform $\rightarrow$ consult $\rightarrow$ collaborate $\rightarrow$ stakeholder directed) [7]. Likewise, there is a need for processes that actively engage stakeholders in formulating and implementing CCC research agendas.

Community-Based Participatory Research (CBPR) and Comprehensive Participatory Planning and Evaluation (CPPE) processes are two promising approaches to address this gap. Effective CBPR initiatives leverage the collective knowledge, expertise, and resources of communityacademic partnerships to develop and execute culturallyrelevant and community-prioritized interventions $[8,9]$.
The CPPE process is a five step, action-oriented approach designed to guide project planning and evaluation [1012]. Furthermore, the Comprehensive Cancer Control National Partnership has developed the Nine Habits of Successful Comprehensive Cancer Control Coalitions (Nine Habits) to guide development and evaluation of CCC efforts [13, 14]. Relying on these approaches and resources to advance CCC efforts is especially important among rural, health disparate communities, where cancer disparities persist [15-17].

\section{Cancer disparities context in the rural, Appalachia region of Southwest Virginia}

While there has been notable CCC progress among state and local cancer coalitions [18-22], cancer remains a leading cause of death in rural populations, and ruralurban disparities persist [17, 23, 24]. Compared to other US counties, rural Appalachian counties have poorer cancer-related health outcomes across the cancer care continuum and suffer from persistent disparities [2531]. Notably, southwest Virginia and other Appalachian regions face a higher mortality-incidence ratio than other US areas [28]. Lower cancer incidence rates in southwest Virginia is symptomatic of lack of early screening and detection, whereas, higher mortality rates are indicative of later stage diagnosis and lack of access to treatment and cancer survivorship support programs. Specifically, there are noted breast, cervical, colorectal, and lung cancer disparities [25-31]. Additionally, the region faces high prevalence of cancer related risk factors, 
including higher rates of obesity and tobacco use and lower rates of cancer screening and physical activity [26, 32].

\section{History of the Southwest Virginia community-academic advisory board (CAB)}

In 2013, the University of Virginia (UVA) formed a regional Community-Academic Advisory Board ( $\mathrm{CAB}$ ) to engage local stakeholders in addressing cancer disparities and access to care in rural, southwest Virginia. The CAB's mission was to provide guidance to ensure cancer control and prevention programs and research served the best interests of residents living and working in the represented health districts. Initial efforts were supported by UVA's Cancer Center. However, these efforts were neither structured within CBPR initiatives nor adequately funded to provide dedicated staff and technical assistance for regional coalition development.

From 2013 to 2017, the CAB grew to include over 30 representatives from three health districts representing 13 counties in southwest Virginia. Governed in accordance to by-laws and with three formal meetings per year, the $\mathrm{CAB}$ was co-chaired by three volunteer community members, representing each health district. Primary achievements of the $C A B$ during this time included 1) identifying regional needs and opportunities, 2) assisting in coordinating cancer outreach programs, and 3) providing insight on feasibility of research projects and collaborate on initiatives. Building from these accomplishments, in 2017, timing was optimal to elevate local leadership and restructure the $\mathrm{CAB}$ to develop, prioritize, and implement a regional cancer control research agenda. This paper describes the CAB's process of transitioning to a community-driven and action-oriented cancer control research agenda in rural Appalachia and highlights the experience of involved stakeholders.

\section{Objectives}

This engagement project focused on strengthening the infrastructure of the $\mathrm{CAB}$, including advancing the knowledge, competencies, and abilities of $C A B$ members to participate in developing and executing patientcentered CCC research and outreach projects. The objectives of this paper are to 1) describe processes that were used to prioritize regional CCC needs, along with intermediate outcomes and 2) detail longitudinal findings (i.e., challenges, strengths, recommendations) from a capacity evaluation. The goals of this engagement project were to increase knowledge exchange and advance the CAB's readiness and capacity to prioritize and act on cancer-related disparities in rural Appalachia. In accordance with Guidance for Reporting Involvement of Patients and the Public (GRIPP), this study meets all five criteria for quality, consistency, and transparency in patient and public involvement as outlined on the GRIP P2 short form checklist [33].

\section{Methods}

This three-year case study (2017-2020) and process evaluation describes $\mathrm{CAB}$ advancement using a convergent parallel mixed-methods design [34, 35]. The approach and evaluation were guided by CBPR principles $[8,9]$, the CPPE process [10-12], the Nine Habits [13, 14], and coalition evaluation literature [36]. The UVA Intuitional Review Board approved this project. $\mathrm{CAB}$ members provided signed informed consent before participating in the evaluation.

\section{CAB membership}

At the start of this project, there were 69 (53 community, 16 academic) active $\mathrm{CAB}$ members. Approximately two-thirds $(65 \%)$ were members for a year or more, while about one-third (35\%) were newer $C A B$ recruits. $\mathrm{CAB}$ members represented community health centers and free clinics, hospitals and health systems, training institutions, and advocacy groups across southwest Virginia. Many members were also cancer survivors and/or caregivers (see Fig. 1). UVA Cancer Center outreach and engagement staff and academic partners from the UVA School of Medicine, Department of Public Health Sciences, and School of Nursing also served on the CAB.

\section{Meeting structure and the CPPE steps}

At the start of this project, $\mathrm{CAB}$ members extended the half-day in person meetings from three to four times per year. These meetings consisted of two hours dedicated to sharing updates along with one featured community spotlight and one featured research project. The last two hours of the meetings were dedicated to engaging $C A B$ members in the CPPE process. As the project progressed and priorities were identified, sub-groups began meeting regularly outside of the $\mathrm{CAB}$ meetings via conference calls. Meeting decisions informed subsequent activities (e.g., causal model development, strategy rating tasks, training topic focus). A website was developed to share meeting minutes and other resources [37].

The CPPE process is a five step multi-phased and action-oriented approach designed to guide project planning and evaluation. The steps include: (Step 1) problem assessment, (Step 2) identification and selection of potential interventions, (Step 3) planning, (Step 4) setting up a monitoring and evaluation system, and (Step 5) proposal development [10-12]. Each step is flexible with an emphasis on community participation. Given the breadth of cancer disparities and potential cancer control focus areas, the CAB started at Step 1. 


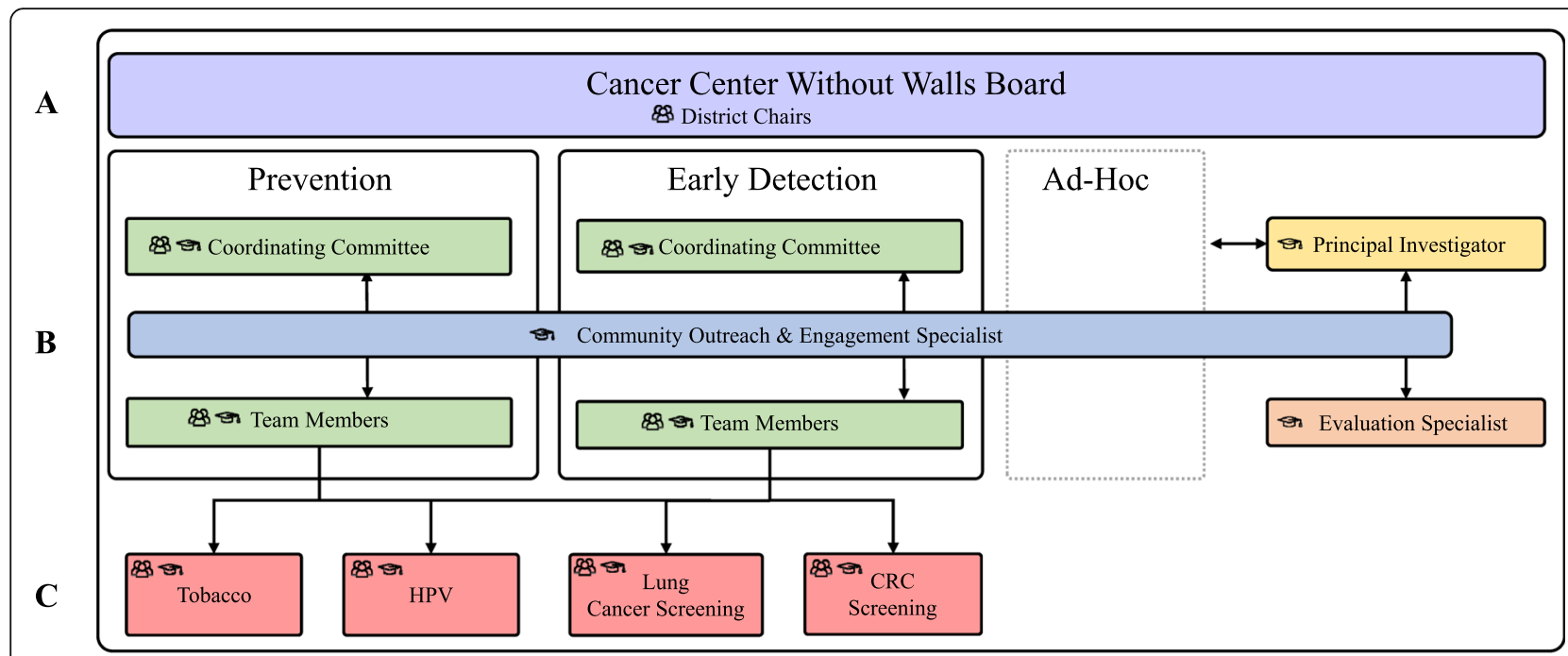

Key

89 Community Partner: primary partners include American Cancer Society, American Lung Association, Ballad Health, Clinch River Health Services, Clinch Valley Medical Center, Cumberland Plateau Health District, Emory \& Henry College, The Health Wagon, Lenowisco Health District, Mount Rogers Health District, Mountain Empire Community College, Mountain Empire Older Citizens, Scott County School District, Stone Mountain Health Services, Tri-Area Community Health, Virginia Cooperative Extension

Academic Partner: UVA faculty, research staff, and Cancer Center Outreach \& Engagement Staff

A = organizational structure in place prior to PCORI Engagement Project

$\mathbf{B}=$ organizational structure (Action Teams) added at the start of the PCORI Engagement Project

C $=$ organizational structure (Priority area specific sub-committees) added after the identification of the priority cancer control priorities

Fig. 1 Evolving structure of the Community Advisory Board

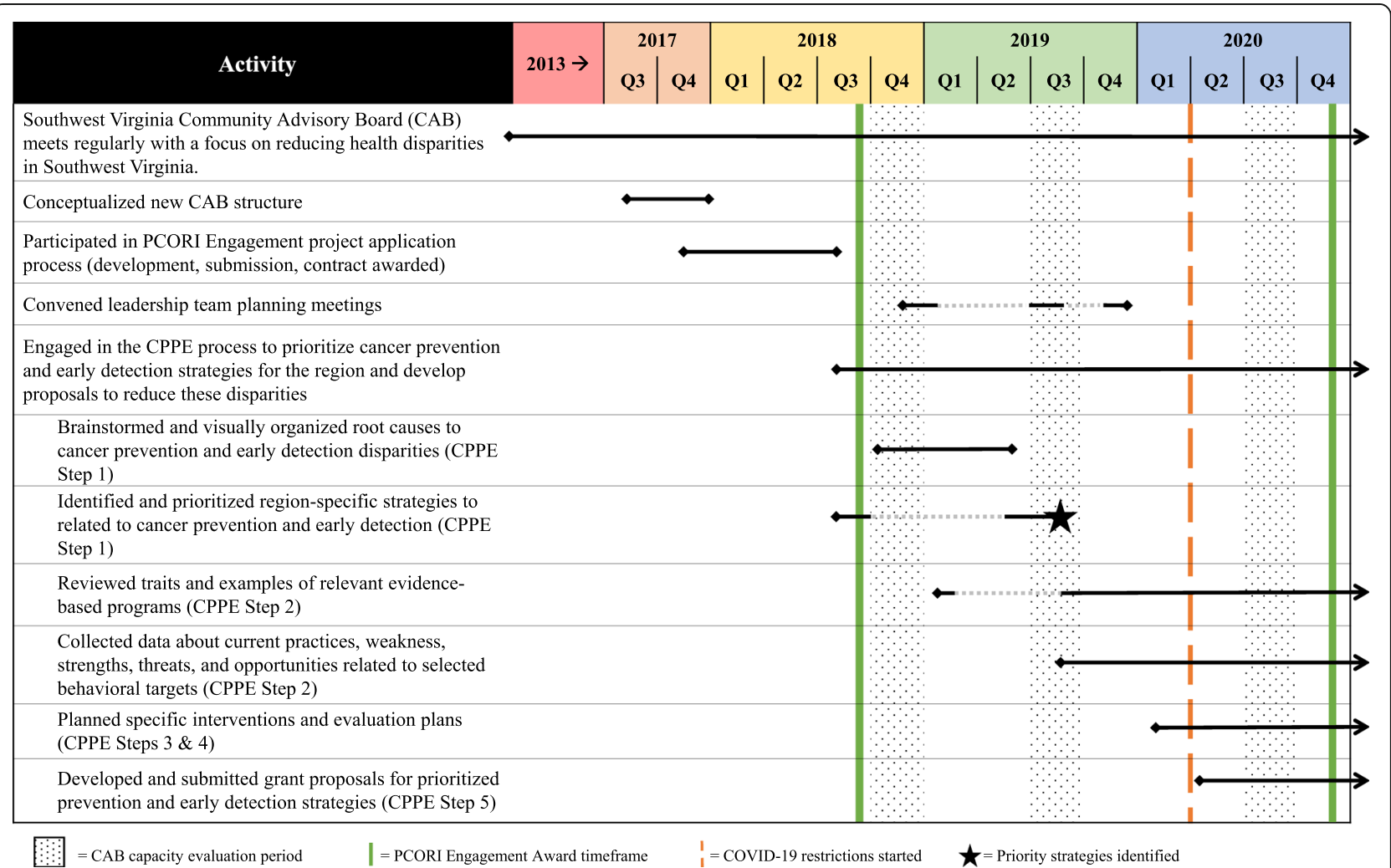

Fig. 2 Overview of the capacity building timeline and processes 


\section{Mixed-methods process evaluation}

Quantitative and qualitative data were collected simultaneously, analyzed independently, and triangulated during the data interpretation phase. Over a three-year timespan, $\mathrm{CAB}$ meeting agendas, minutes, and meeting artifacts were collected. Additionally, CAB members completed a quantitative survey at three time points (Time $1=$ Summer 2018, Time $2=$ Summer 2019, Time $3=$ Summer 2020) and semi-structured telephone interviews at two time points (Time $2=$ Summer 2019, Time 3 = Summer 2020) (see Fig. 2).

The quantitative survey and semi-structured qualitative interview guide were guided by the Nine Habits. The habits were reviewed for relevance to the context of the CAB as well as to the CPPE processes. Seven of the habits were measured, along with trust and satisfaction. Previously developed and validated scales were used to assess each construct [36, 38-41]. Habit descriptions, scale sources, number of items are reported in Table 1. Members completed the survey either at a $C A B$ meeting or via a web-based link. Three trained UVA staff conducted interviews that lasted approximately 30 (range 20-90) minutes.

\section{Analysis}

Quantitative and qualitative data were first analyzed independently [34, 35, 42]. Quantitative data were analyzed using SPSS. Researchers conducted factorial ANOVAs to explore changes in habit ratings over time by $\mathrm{CAB}$ member type (academic or community). To determine potential bias of inclusion of less active members' data in factorial ANOVAs, the same analysis between time and members type was conducted using a repeated measures ANOVA limited to $C A B$ members who completed the rankings at all three time points.

For qualitative data, interviews were audio-recorded and transcribed verbatim. NVivo 1.2 software was used to manage the hybrid inductive-deductive coding process [43, 44]. Coding took part over four stages, whereby coders maintained memos that identified emerging codes and changes to code definitions [45]. At each coding stage, transcripts were coded independently by two trained researchers and reconciled collectively to resolve discrepancies and refine the codebook. When an agreement could not be reached, a third coder helped resolve discrepancies.

For the first stage of coding, transcripts were segmented into habit constructs. This was followed by the second stage in which coders' memos during initial segmentation were used to develop codes and definitions reflecting strengths, challenges, and recommendations for each habit. The third stage involved the review of all codes by two researchers to condense overlapping definitions within each habit and across all recommendations. The frequency by which $\mathrm{CAB}$ members mentioned each code was calculated to identify prominence of the codes across the two time points [42]. The fourth stage of coding involved member checking and a final reconciliation. Member checking occurred using a summarized qualitative data report, whereby $\mathrm{CAB}$ members were asked to review code definitions, counts, and quotes for strengths, challenges, and recommendations

Table 1 Habit descriptions and quantitative scale source and Cronbach's alpha

\begin{tabular}{|c|c|c|}
\hline Habit & Description & $\begin{array}{l}\text { Number of } \\
\text { items }\end{array}$ \\
\hline $\begin{array}{l}\text { Effective } \\
\text { communication }\end{array}$ & $\begin{array}{l}\text { CAB communication is consistent, purposeful, and uses multiple channels for discussion (e.g., email, Web, } \\
\text { live/virtual meetings). }\end{array}$ & 7 \\
\hline Priority work plans & $\begin{array}{l}\text { Evidence based strategies inform priorities and work plans. Work plans are adaptable and clearly outline } \\
\text { outcomes, methods, responsibilities, and timelines that guide CAB efforts. }\end{array}$ & 6 \\
\hline $\begin{array}{l}\text { Clear roles and } \\
\text { accountability }\end{array}$ & $\begin{array}{l}\text { Roles are clearly communicated to CAB members who understand their responsibilities and are accountable } \\
\text { for task completion. }\end{array}$ & 4 \\
\hline $\begin{array}{l}\text { Shared decision } \\
\text { making }\end{array}$ & Shared decision making guides the CAB and procedures are outlined to avoid imbalances in power. & 10 \\
\hline $\begin{array}{l}\text { Value-added } \\
\text { collaboration }\end{array}$ & $\begin{array}{l}\text { CAB members acknowledge and appreciate the benefits of collaboration and recognize the power of their } \\
\text { collected efforts. }\end{array}$ & 7 \\
\hline $\begin{array}{l}\text { Empowering } \\
\text { leadership }\end{array}$ & $\begin{array}{l}\text { Leaders encourage active participation in decision making by all CAB members. This empowerment builds } \\
\text { trust and accountability. }\end{array}$ & 10 \\
\hline Diversified funding & $\begin{array}{l}\text { Diversified funding can create wider support/involvement in CAB efforts and can secure viability if one } \\
\text { funding source disappears. }\end{array}$ & 6 \\
\hline Trust & $\begin{array}{l}\text { The degree to which } C A B \text { members rely on one another to share information, follow through on tasks, and } \\
\text { remain committed. }\end{array}$ & 3 \\
\hline Satisfaction & Satisfaction with work plan development and execution, goal progress, and allocation of resources. & 3 \\
\hline
\end{tabular}

Trust and satisfaction are not habits define by the Comprehensive Cancer Control National Partnership, yet were prioritized and measured constructs for this engagement project. Also, to limit the overall survey and interview length, the habits of dedicated staff and flexible, as defined by the Comprehensive Cancer Control National Partnership, were not measured 
[46]. Through this process, 22 members responded to three questions and overwhelming verified that their own experiences were represented and that nothing was missing or misrepresented in the data.

Finally, data triangulation was conducted $[34,35]$. The intention was to clarify consistencies and contradictions between meeting artifacts and $C A B$ outputs, as well as distinctions between quantitative and qualitative $C A B$ data strands. This synthesis is presented in the discussion.

\section{Results}

\section{CAB member participants}

Meeting attendance fluctuated, with an average attendance of $28 \mathrm{CAB}$ members, including 16 community and 12 academic members. Of 69 active members at the start of the CPPE process, 49 (71\%) signed a consent to participate in the evaluation. At Time 1,2, and 3, respectively, 45, 32, and $24 \mathrm{CAB}$ members completed the survey, while 37 and $28 \mathrm{CAB}$ members completed the interview at Time 2 and 3 , respectively.

\section{Overall time and activities}

Figure 2 provides a timeline of $\mathrm{CAB}$ activities and accomplishments. Between June 2017 and September 2020, $C A B$ members engaged in CPPE-related activities to identify and strategize how to address regional cancer priorities. During this time, there were 13 full $C A B$ meetings and two additional training opportunities. Outside of larger meetings, the Prevention and Early Detection Action Teams met an additional four times and, after the four priority areas were identified, sub-groups met six times. A key goal of these meetings and trainings was to increase knowledge exchange pertaining to CCC planning and evidence-based cancer control resources. As such, shared and discussed resources included, but were not limited to the Virginia Cancer Plan [47], Evidence-Based Cancer Control Programs (formerly RTIPs) [48], Community Preventive Service Task Force guide [49], American Cancer Society screening recommendations [50], and Putting Public Health Evidence in Action [51].

Concurrent with engaging in CPPE steps, community and academic $C A B$ members participated in leadership and general capacity building activities. Two in-person, 1$1 / 2$ day leadership retreats were held at UVA (December 2018, November 2019). Community CAB members and academic leaders reviewed $C A B$ progress and presented to and heard from UVA faculty members whose research was aligned with cancer control priorities. Additionally, a patient-centered outcomes research presentation was held in April 2019 for UVA faculty and a webinar pertaining to social marketing for health behaviors was held for $C A B$ members and other Cancer Action Coalition of Virginia affiliates in February 2020.

\section{CPPE process preparation and $C A B$ restructuring}

$\mathrm{CAB}$ members prepared to engage in the CPPE process between June 2017 and April 2018 (Fig. 2). Over four meetings, $C A B$ members reviewed the cancer control continuum and engaged in guided conversations about potential focus, goals, and impacts. $\mathrm{CAB}$ members also completed a membership matrix (i.e., organization mission, clientele, staffing, support, allies, interests, future involvement) and brainstormed structures for $C A B$ reorganization. These activities led to a new $C A B$ structure that included Cancer Prevention and Early Detection Actions Team (Fig. 1). These two areas of focus reflected regional cancer data, members' experience, and organizational missions. The plan included an emphasis on disparities and plans for community and academic member co-leadership. Also, a decision was made to allow ad-hoc sub-groups to address other cancer control priorities, such as survivorship. In anticipation of strategy development during the future CPPE process, $\mathrm{CAB}$ members reviewed the Virginia Cancer Plan [47] and data reports highlighting southwest Virginia regional needs specific to prevention and early detection. Collectively, these activities led to the collaborative development of a Eugene Washington PCORI Engagement proposal submission and an awarded contract to support continued $\mathrm{CAB}$ engagement.

\section{CPPE process: steps 1 through 5}

As demonstrated in Fig. 2, between November 2018 and September 2019, the CAB participated in three quarterly meetings to engage in problem assessment activities (CPPE Step 1). Activities were facilitated by an external consultant with expertise in CBPR and large group processes. Consistent with CPPE Step 1a (Fig. 2), Action Teams brainstormed root causes for regional cancer prevention and early detection disparities and then developed and refined causal models reflecting root causes (see Supplementary Figs. 1 and 2). Subsequently, Action Teams completed CPPE step 1b (Fig. 2) through a prioritization process to identify the top strategies that could have the most impact on regional cancer disparities. Strategies from the Virginia Cancer Plan [47] were rated on their importance and feasibility. Action Teams then reflected on and discussed ratings in the context of causal models, organizational abilities, and existing regional activities. After several meetings, four priority needs were identified: (1) improving patient and provider education around HPV vaccination, (2) increasing evidence-based tobacco education and behavioral change interventions, (3) increasing advocacy, awareness and screening rates for colorectal cancer (CRC), and (4) 


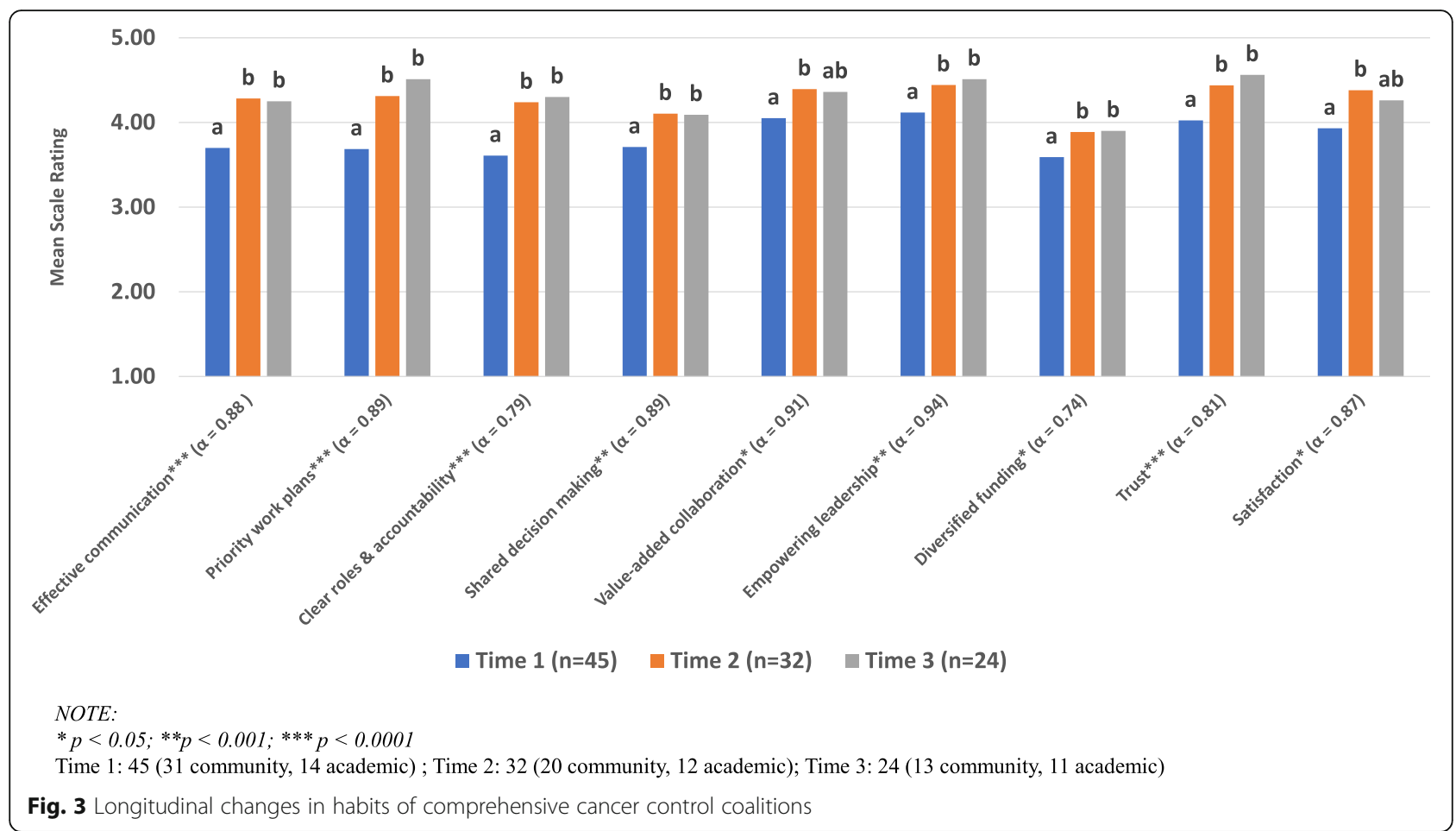

increasing advocacy, awareness and screening rates for lung cancer.

$\mathrm{CAB}$ members proceeded to CPPE Step 2 through engagement in intervention identification activities. Academic members initiated CPPE Step 2a in February 2019 with a webinar on the science behind evidenced-based programs using examples of cancer prevention and early detection interventions conducted in other rural and/or Appalachian communities (Fig. 2). Then, in Fall of 2019, Action Teams started reviewing evidenced-based interventions related to the CAB's four targeted strategies. As part of CPPE Step 2b (Fig. 2), this review identified potential individual, system, and social barriers and facilitators to implementing the identified strategies.

Starting in early 2020, sub-groups began to plan specific interventions (CPPE Steps 3 and 4) and submit grant proposals (CPPE Step 5). Due to COVID-19, all of these meetings were conducted virtually. At the time of this paper submission (Winter 2020), the following sub-group progress has occurred: 1) submission of two research grant applications related to HPV vaccination projects, 2) collection of pilot data for a tobacco-based project involving regional pharmacies to develop a research grant application, 3) development of a small media campaign to increase CRC screening rates among four Federally Qualified Health Centers for release during CRC Awareness Month in March 2021, and 4) review of the literature and planning for the potential development and evaluation of a decisional aid related to low-dose computed tomography lung cancer screenings.

\section{Quantitative capacity findings}

Internal reliability for each habit subscale was analyzed using Cronbach alpha. Overall, scale consistencies were deemed acceptable for each habit (Cronbach $\alpha=0.74$ 0.94; see Fig. 3). As illustrated in Fig. 3, habits were ranked relatively high at Time 1 , and all habits significantly improved at Time 2 (all $p<.05$ ). At Time 3 , most habits remained significantly higher than Time 1 (all $p<.05)$. Two exceptions were value-added collaboration and satisfaction, which dipped slightly at Time 3 and were no longer significantly different from Time 1 and Time 2 . When analyzing data only from $C A B$ members who completed quantitative rankings at each time point ( $n=16-19$ CAB members per habit), findings and interpretations were remarkably similar (data not shown). Likewise, there were no meaningful differences among community and academic members' ratings of habits (data not shown).

\section{Qualitative capacity findings}

Across habits and at both Time 2 and Time 3 interviews, strengths reported by $\mathrm{CAB}$ members outweighed the challenges in both quantity and frequency (Table 2). An exception was for diversified funding, where reported strengths and challenges were relatively more even. Related to challenges, limited time was consistently mentioned across most habits and was viewed as a limiting factor at both time points. Also, implications of COVID19 , especially as it related to effective communication and diversified funding, emerged as a major challenge at 


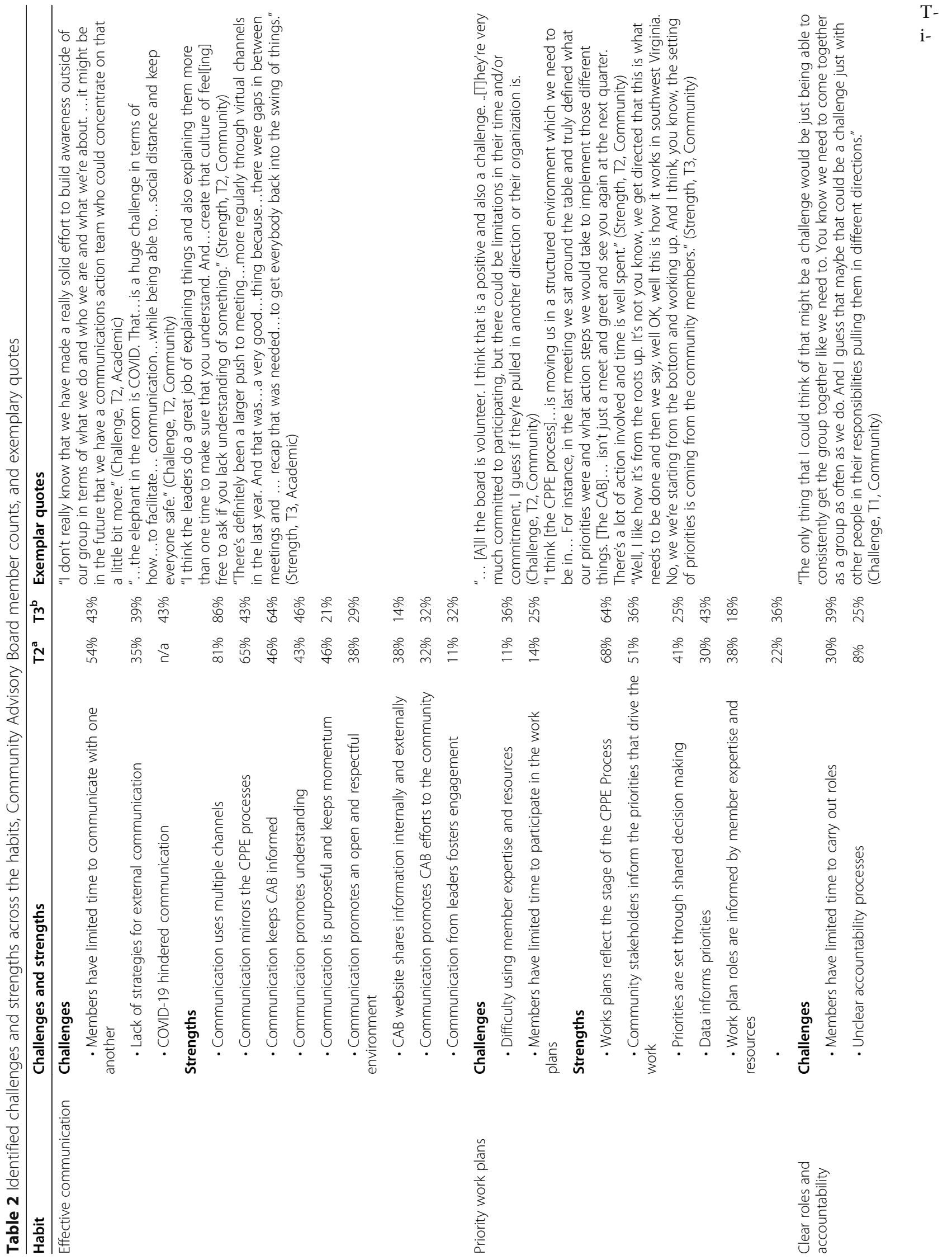




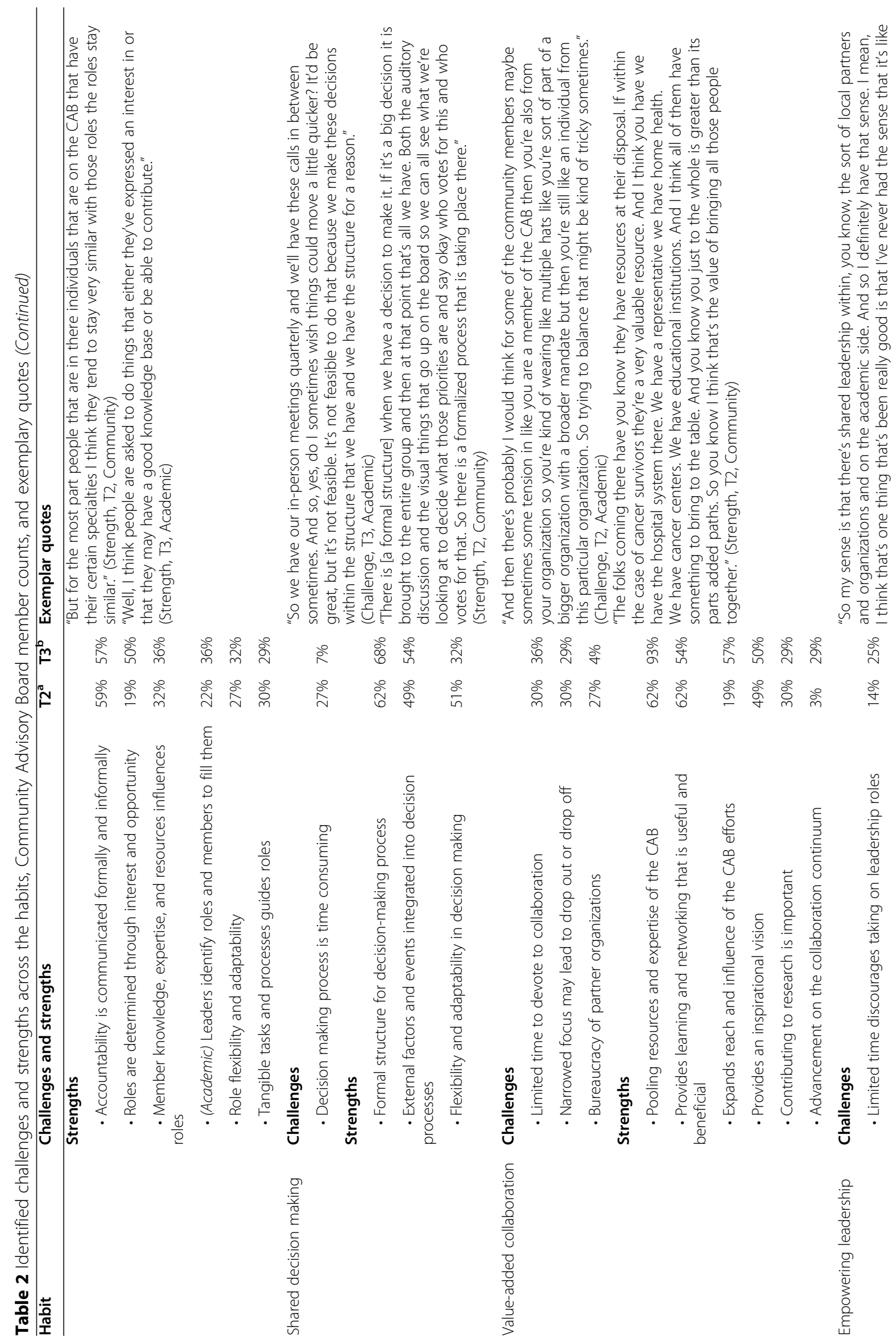




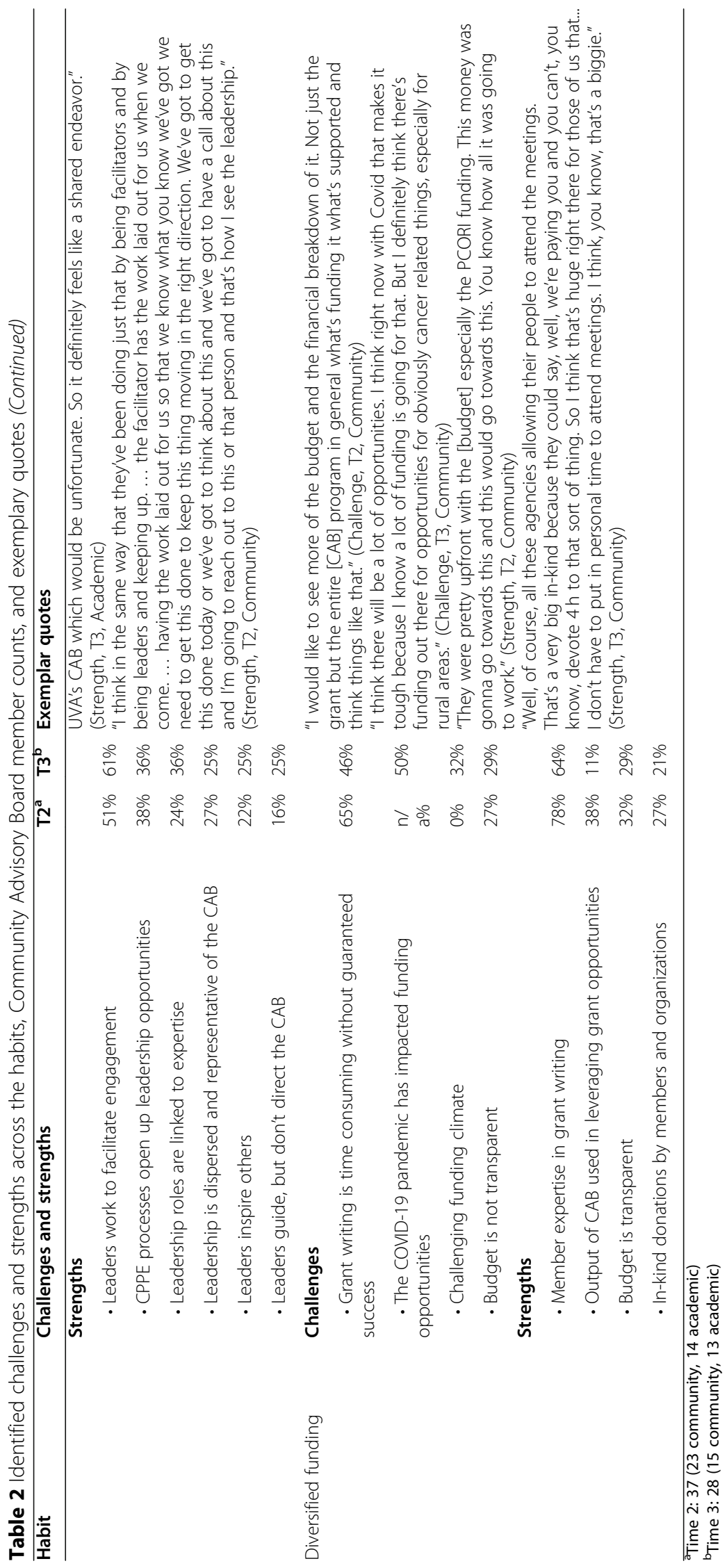


me 3. Many other challenges remained relatively consistent between time points. However, a few challenges decreased from Time 2 to Time 3, including time consuming decision making processes (shared decision making) and bureaucracy of partner organizations (value-added collaboration). Alternatively, a few challenges increased somewhat from Time 2 to Time 3, including difficulty using member expertise and resources (priority work plans), unclear accountability processes (clear roles and accountability), and challenging funding climate (diversified funding).

As illustrated in Table 2, multiple strengths for each habit were identified at both time points. Similar to challenges, the content and frequency of strengths were fairly consistent from Time 2 to Time 3, with a few notable exceptions. Throughout the CPPE process, CAB members increasingly recognized benefits of the collaboration, including pooling of resources and the collective ability to have greater regional influence (value-added collaboration). Additionally, between Time 2 and Time 3, CAB members more frequently expressed opportunity for roles for which they were passionate (clear roles and accountability) and trusted leadership to identify roles and guide $\mathrm{CAB}$ efforts (empowering leadership). Furthermore, there was increased frequency of identifying how effective communication kept members informed and fostered engagement. Alternatively, at Time 3, CAB members less frequently mentioned purposeful communication and the website as strengths (effective communication). There were also decreases in frequency of perceptions concerning the CAB's leveraging of community partner expertise to inform priorities and work plans (priority work plans), flexibility around decision making (shared decision making), and ability to obtain grant funding (diversified funding) between Time 2 and Time 3 .

As shown in Table 3, interviews identified nine key recommendations that cut across the habits. Recommendations reflect opportunities to promote multiple stakeholder perspectives, recruit new members, seek diverse funding sources, improve internal and external communication, develop sustainability plans, identify and leverage resources, expand leadership, and enhance ownership of $C A B$ efforts. Overall, $C A B$ members mentioned most recommendations at a relatively consistent frequency at both time points. However, relative to Time 2, at Time $3 \mathrm{CAB}$ members more frequently recommended efforts to improve external communication strategies, expand pathways to leadership roles, and enhance ownership of $C A B$ efforts.

\section{Discussion}

Advancing, managing, and sustaining CCC coalition efforts is not an organic process. Rather, it takes concerted efforts and thoughtful, purposeful partnership building

Table 3 Key recommendations to promote capacity for regional, rural comprehensive cancer control across the habits

\begin{tabular}{|c|c|c|c|c|c|c|c|c|c|}
\hline \multirow[t]{2}{*}{ Recommendations } & \multicolumn{7}{|c|}{ Associated Habits } & \multirow{2}{*}{$\begin{array}{l}\text { Time } \\
2 \% \\
\text { (of } \\
37)\end{array}$} & \multirow{2}{*}{$\begin{array}{l}\text { Time } \\
3 \% \\
\text { (of } \\
28)\end{array}$} \\
\hline & $\begin{array}{l}\text { Effective } \\
\text { communi- } \\
\text { cation }\end{array}$ & $\begin{array}{l}\text { Priority } \\
\text { work } \\
\text { plans }\end{array}$ & $\begin{array}{l}\text { Clear } \\
\text { roles/ } \\
\text { account- } \\
\text { ability }\end{array}$ & $\begin{array}{l}\text { Shared } \\
\text { decision } \\
\text { making }\end{array}$ & $\begin{array}{l}\text { Value-added } \\
\text { collaboration }\end{array}$ & $\begin{array}{l}\text { Empowering } \\
\text { leadership }\end{array}$ & $\begin{array}{l}\text { Diversified } \\
\text { funding }\end{array}$ & & \\
\hline $\begin{array}{l}\text { 1. Use clear communication strategies to } \\
\text { foster clarity and unified understanding } \\
\text { within the } C A B\end{array}$ & $\checkmark$ & & $\checkmark$ & $\checkmark$ & & & $\checkmark$ & $65 \%$ & $75 \%$ \\
\hline $\begin{array}{l}\text { 2. Improve external communication } \\
\text { strategies to promote } C A B \text { efforts }\end{array}$ & $\checkmark$ & & & & & & & $43 \%$ & $64 \%$ \\
\hline $\begin{array}{l}\text { 3. Strategically recruit new members for } \\
\text { mission enhancement }\end{array}$ & & & & & $\checkmark$ & $\checkmark$ & & $38 \%$ & $32 \%$ \\
\hline $\begin{array}{l}\text { 4. Seek diverse funding to sustain } C A B \\
\text { operations/work plan projects }\end{array}$ & & & & & & & $\checkmark$ & $35 \%$ & $39 \%$ \\
\hline $\begin{array}{l}\text { 5. Promote an open, equitable space for } \\
\text { multiple perspectives }\end{array}$ & & & $\checkmark$ & $\checkmark$ & & $\checkmark$ & $\checkmark$ & $33 \%$ & $25 \%$ \\
\hline $\begin{array}{l}\text { 6. Develop formal processes to support CAB } \\
\text { sustainability (e.g., funding capacity, } \\
\text { accountability structures, collaborative } \\
\text { action planning) }\end{array}$ & & $\checkmark$ & $\checkmark$ & & $\checkmark$ & & $\checkmark$ & $24 \%$ & $29 \%$ \\
\hline $\begin{array}{l}\text { 7. Expand pathways for members to obtain } \\
\text { leadership roles and/or positions }\end{array}$ & & & $\checkmark$ & & & $\checkmark$ & & $14 \%$ & $25 \%$ \\
\hline $\begin{array}{l}\text { 8. Enhance perceptions of ownership in } C A B \\
\text { efforts by } C A B \text { members and their } \\
\text { respective organizations }\end{array}$ & & & $\checkmark$ & & $\checkmark$ & & & $11 \%$ & $29 \%$ \\
\hline $\begin{array}{l}\text { 9. Identify, secure, and leverage existing and } \\
\text { needed } C A B \text { resources }\end{array}$ & $\checkmark$ & & $\checkmark$ & & $\checkmark$ & $\checkmark$ & & $11 \%$ & $18 \%$ \\
\hline
\end{tabular}


approaches [13]. Despite steady US progress pertaining to CCC efforts over the past two decades $[18,19]$, evidence suggests that rural communities are lagging behind [15-17]. Thus, there is a clear need to link cancer control outreach and engagement efforts with research efforts. Numerous studies document the promise of CBPR approaches in achieving this link. Examples include the value of community involvement in promoting high intervention ownership and considering organizational capacity [52], the necessity of equalizing power distribution within diverse partnerships [53], and the importance of building multi-sector coalitions to strengthen capacity and promote community resiliency [54]. This case study is unique in that we draw from a key community asset (e.g., a functioning $C A B$ with established multi-sector collaboration and history of advising cancer outreach and research projects) and build from prior and on-going successful projects [37, 55-57]. Established coalition building tools were used to work collaboratively with the $\mathrm{CAB}$ to pivot its structure from opportunistic partnering to action oriented planning thereby strengthening its function to address cancer related disparities. The robust process evaluation and mixed-methods approach provided an in-depth and rich reflection of opportunities and challenges in redirecting coalition efforts and advancing community $C A B$ members along the engagement spectrum from informing to stakeholder directed research project [7]. In sum, this case study responds to literature gaps concerning useful processes that can actively engage community members in formulating and implementing CCC research agendas and outreach projects.

The outcomes of our CBPR approach and CPPE processes indicate $\mathrm{CAB}$ success in identifying priority $\mathrm{CCC}$ issues, co-developing research questions, and transitioning into action-oriented intervention testing and implementation in one rural, medically underserved region. Specifically, efforts resulted in the reorganization of the $C A B$ to address key regional cancer needs around prevention and early detection and the building of causal models to identify strategies to address those needs and reduce cancer disparities within the region. These processes spurred collaborative efforts to develop public relation and clinical trial research opportunities surrounding HPV vaccination awareness, tobacco education and cessation programming, and screening for CRC and lung cancer. Furthermore, evaluation of effective $\mathrm{CCC}$ habits was key to providing insight on the internal functioning of the $C A B$ and its readiness to proceed to implementation phases of the CPPE process (e.g., Step 5).

CCC initiatives can be overwhelming, particularly in rural, health disparate regions where epidemiological data and social determinants of health indicators suggest that nearly every cancer control strategy is a priority.
Studies demonstrate that narrowing priorities in these situations are difficult [58]. In our case, the Virginia Cancer Plan has 12 goals that include about 46 objectives and 155 strategies [59]. While the list is comprehensive, addressing each objective is not possible for a regional cancer coalition operating in a medically underserved region. Consistent with these observations, the $\mathrm{CAB}$ readily synthesized data into comprehensive causal models in Step 1 of the CPPE process, but the breadth and depth of regional cancer disparities made prioritization of strategies in Step 2 considerably more difficult. As an example, the Prevention and Early Detection Action Teams struggled to narrow five top rated priorities down to two. To help alleviate this struggle, the CPPE facilitator consistently reminded the CAB of the following: "Saying no right now, doesn't mean saying no forever;" "We can't take on everything and do it all well;" and "We need to concentrate on where high priority in your communities and within your organizations overlap with the potential for high impact." After about six meetings, our $\mathrm{CAB}$ eventually landed on a set of four focused CCC priorities, two within each action team.

Evaluation of CCC coalition best practices revealed key insights into strengths and challenges of our $C A B$. Prior to this engagement project in 2017, the $C A B$ existed for about 4 years, during which time they developed a strong sense of commitment and collaboration. This is reflected in the high quantitative habit ratings at Time 1 . These ratings signify the strong foundations of the partnership and are consistent with the CAB's yearlong restructuring and preparation for an actionoriented agenda. Still, longitudinal evaluation demonstrated continued quantitative improvements in rated habits. Qualitative data, in large part, supported these improvements and suggested that they may be attributed to CPPE and CBPR efforts along with guidance from the National Comprehensive Cancer Control Program's Nine Habits resource.

Positivity of the quantitative data was reflected in $\mathrm{CAB}$ member emphasis on strengths over challenges during the interviews. Moreover, qualitative data suggested an increased sense of efficacy in the CAB's collective abilities as they moved forward in carrying out work plans. Although some identified strengths at Time 2 fluctuated at Time 3, this variation is linked more to changing circumstances surrounding the progression through the CPPE process, the approaching end of current funding, and the COVID-19 pandemic than to reduced or changing capacity of the CAB. For instance, the timeconsuming process of deciding on priorities was in progress during Time 2 interviews and completed by Time 3 , reflecting a decrease in challenges mentioned around timeliness of this activity. Similarly, with evolution from priority setting to action planning, emphasis shifted to a 
need for identifying and utilizing member expertise and resources, thus making this a greater challenge at Time 3 than at Time 2. Uncertainty as the CAB moved forward were demonstrated as some previously mentioned assets waivered, and challenges increased around the diversified funding habit. Due to COVID-19, anxiety was likely heightened because of changes to the funding landscape and to shifting priorities of members and their organizations to deal with a health crisis that may limit their availability to participate in $C A B$ activities [60]. However, despite some uncertainty around transitions in the CPPE process and in potential future funding sources, the $C A B$ was seen as both a solid and a powerful force for change that benefited from diverse representation, committed and passionate members, and experienced leaders. This is the backbone of the $C A B$ that will sustain efforts as they navigate into the next CPPE phase and obtain funding to carry out sub-group work plans.

\section{Ongoing and next steps}

While still somewhat early in the planning, evaluation and proposal development CPPE steps, three examples signify community $\mathrm{CAB}$ members' progression along the engagement spectrum to collaborating and directing projects. First, the HPV sub-group has submitted two research proposals focused on multi-sector capacity building as well as selecting and pilot testing vaccination interventions. Second, one Federally Qualified Health Center partner has led submission of a Health Resources and Services Administration Rural Health Care Services Outreach Program Grant that focused on cancer control. Finally, one of our ad hoc sub-groups has submitted an American Cancer Society research grant to evaluate a cancer survivorship intervention tailored to the needs of rural patients and health systems. Each project focuses on intervening on regional cancer disparities and is guided by evidence-based resources.

After both data collection time points, a summary of key recommendations was shared and discussed at $C A B$ meetings. Efforts to better coordinate internal and external communication were prioritized first [61]. Enacted strategies include development of a website to disseminate $\mathrm{CAB}$ information, launch of a monthly newsletter emailed to $C A B$ members, coordinated and standing teleconference sub-group meetings, and launch of a local newspaper series to promote external $C A B$ visibility and to raise awareness about pertinent cancer priorities. As the $C A B$ continues its sub-group structure transition, recruiting new members and perspectives has emerged as the next priority, especially since the sub-group structure may stretch members too thin and negatively impact participation. Similarly, promoting a shared leadership structure within the sub-groups and stimulating communication within and across sub-groups is imperative to our continued efforts.

A future challenge and opportunity for the UVA Cancer Center is to remain accountable to the $C A B$ and $\mathrm{CPPE}$ process. This involves continuing to infuse resources, such as regional pilot projects and technical assistance to support the CAB's function, as well as bringing research content and CBPR expertise to the table to match community-identified priorities and leverage external resources.

Although the PCORI engagement contract has ended, the action-oriented processes will continue. As stated by Pyron and colleagues, the interaction of a CCC program can be summed up with three Ps: partnerships, CCC plans, and CCC program interventions [21]. While our $\mathrm{CAB}$ has made great strides by harmonizing partnerships and focusing priority plans, we are in the infancy of planning and implementing $\mathrm{CCC}$ program interventions. The CPPE framework continues to serve as our framework as we plan projects and develop proposals. As the $\mathrm{CAB}$ sub-group efforts advance, we continue to rely on evidence-based resources [48-51]. Likewise, as we strategizes on real-world application and sustainability of efforts in practice-based settings across rural Appalachia, participatory implementation science is at the forefront of our agenda [62].

\section{Limitations}

Primary limitations of our case study is the relatively small sample and potential lack of generalizability. While we were able to detect statistically significant changes in the habits over time, limited statistical power may have impacted lack of significant difference detected between community and academic members. Also, our CCC project is embedded within a unique set of contextual factors in rural Appalachia and the identified challenges, strengths, and recommendations are unique to our circumstances. Moreover, we provide frequency counts to help triangulate quantitative and qualitative findings and to explore shifts in $\mathrm{CAB}$ perspectives over time [42]; however, there are some limitations on drawing meaning from frequency counts. Finally, we relied on the Nine Habits to help conceptually guide our process, yet decided to use other validated scales with high psychometric properties instead of those offered in the resource guide $[13,14]$. Despite these limitations, our study also has several strengths. Examples include the mixedmethods study design, application of a strong conceptual framework, use of an external facilitator to guide group processes, number and diversity of interviewed participants, member checking to verify findings, and robust hybrid inductive-deductive qualitative analysis. Other program planners and researchers may be able to apply our methodologies to advance priority setting and 
capacity building in their own coalition advancement efforts.

\section{Conclusions}

This engagement project exemplifies an equity-based participatory approach aimed at setting and advancing a research agenda to address persistent gaps in rural cancer control in Appalachia. The CBPR approach used a CPPE process in conjunction with internal evaluation of CCC coalition best practices to advance $C A B$ efforts. We intend to actively engage the $C A B$ in priority identification and capacity development and are optimistic that doing so will enhance the likelihood that they will remain highly involved in CCC projects. Continued efforts to augment $\mathrm{CAB}$ identified strengths, attend to specific challenges, and enact concrete tactics to address emergent recommendations will be key to the CAB's sustained engagement and future impact on regional cancer disparities. These engagement processes may serve as a template for similar coalitions in rural, underserved areas. The demand for action-oriented partnership development and need to translate evidence-based CCC research into practice is especially high among disadvantaged, rural regions that face countless cancer control and social determinants of health inequities. CPPE process may be an effective means for guiding these coalitions to action. Likewise, strong coalitions are sustained through buy-in, meaning members participate in and are vested in planning, implementation, and evaluation [21, 63]. Evaluating coalitions for effective practices is a means to identify strengths, continued challenges, and opportunities that promote discussion and action around strengthening members' commitment as well as coalition structure and processes.

\section{Abbreviations \\ CAB: Community-Academic Advisory Board; CBPR: Community-based participatory research; CPPE: Comprehensive Participatory Planning and Evaluation; CCC: Comprehensive cancer control; CDC: Centers for Disease Control and Prevention's; NCCCP: National Comprehensive Cancer Control Program; NCl: National Cancer Institute's; NIH: National Institutes of Health; PCORI: Patient-Centered Outcomes Research Institute; US: United States; UVA: University of Virginia; HPV: Human papillomavirus; CRC: Colorectal cancer}

\section{Supplementary Information}

The online version contains supplementary material available at https://doi. org/10.1186/s40900-021-00285-y.

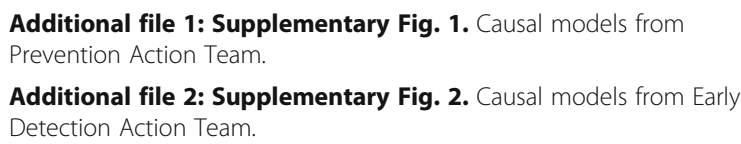

\section{Acknowledgements}

We would like to acknowledge the contributions of the Southwest Virginia Community-Academic Advisory Board members. We would also like to acknowledge the data coding assistance from Jacob Nottingham and Esther Thatcher.

\section{Authors' contributions}

This study was primarily conceived by JZ with input from KP and EM. Under the supervision of JZ, data collection and coding was completed by D-JB, BR, and NV, and data analysis was completed by D-JB and KP. All authors were active members in the meetings and engagement processes, including assuming leadership roles for the subcommittees. JZ drafted the paper with section contributions from D-JB and KP. All authors provided feedback on the manuscript draft and approved the final version.

\section{Funding}

This study was funded by a Eugene Washington Engagement Award Program at the Patient-Centered Outcomes Research Institute (PCORI) contract (\#10254). The project was also supported, in part, by the University of Virginia Cancer Center Support Grants (CA044579).

\section{Availability of data and materials}

Not applicable.

\section{Declarations}

Ethics approval and consent to participate Approval was obtained from the University of Virginia Intuitional Review Board. The procedures used in this study adhere to the tenets of the Declaration of Helsinki. Informed consent was obtained from all individual participants included in the study.

\section{Consent for publication}

Not applicable.

\section{Competing interests}

The authors have no relevant financial or non-financial interests to disclose.

\section{Author details}

${ }^{1}$ Department of Public Health Sciences, School of Medicine, University of Virginia, 16 E. Main St, Christiansburg, VA 24073, USA. ${ }^{2}$ School of Nursing, University of Virginia, PO Box 800782, Charlottesville, VA 22908, USA. ${ }^{3}$ Tri-Area Community Health, P.O. Box 9, Laurel Fork, VA 24352, USA. ${ }^{4}$ Mountain Empire Community College Nursing Program, Phillips-Taylor Hall Rm 136, 3441

Mountain Empire Rd, Big Stone Gap, VA 24219, USA. ${ }^{5}$ Department of Public Health Sciences, University of Virginia, School of Medicine, P.O. Box 800717 , Charlottesville, VA 22908, USA. ${ }^{6}$ Office of Outreach and Engagement, University of Virginia Cancer Center, Box 800334, Charlottesville, VA 22908, USA. ${ }^{7}$ Mountain Laurel Cancer Support and Resource Center, Mountain Empire Older Citizens, Inc., P.O. Box 888, Big Stone Gap, VA 24219, USA. ${ }^{8}$ Clinch Valley Medical Center, 6801 Gov. G. C. Peery Hwy., Richlands, Virginia 24641, USA. ${ }^{9}$ Kingsport, TN, USA. ${ }^{10}$ Office of Community Outreach \& Engagement, University of Virginia Cancer Center, P.O. Box 800334,

Charlottesville, VA 22903, USA.

Received: 2 March 2021 Accepted: 18 May 2021

Published online: 22 June 2021

References

1. Mercer SL, DeVinney BJ, Fine LJ, Green LW, Dougherty D. Study designs for effectiveness and translation research: identifying trade-offs. Am J Prev Med. 2007;33(2):139-154.e132. https://doi.org/10.1016/j.amepre.2007.04.005.

2. National Academies of Sciences, Engineering, and Medicine. Guiding Cancer Control: A Path to Transformation. Washington, DC: The National Academies Press; 2019. https://doi.org/10.17226/25438.

3. Bodison SC, Sankare I, Anaya H, Booker-Vaughns J, Miller A, Williams P, et al. Engaging the Community in the Dissemination, implementation, and improvement of health-related research. Clin Transl Sci. 2015;8(6):814-9. https://doi.org/10.1111/cts.12342.

4. Tapp H, White L, Steuerwald M, Dulin M. Use of community-based participatory research in primary care to improve healthcare outcomes and disparities in care. J Comp Eff Res. 2013;2(4):405-19. https://doi.org/10.2217/ cer.13.45. 
5. Cargo M, Mercer S. The value and challenges of participatory research: strengthening its practice. Annu Rev Public Health. 2008;29(1):325-50. https://doi.org/10.1146/annurev.publhealth.29.091307.083824.

6. Viswanathan M, Ammerman A, Eng E, Garlehner G, Lohr KN, Griffith D, et al. Community based participatory research: assessing the evidence: summary. In AHRQ evidence report summaries. Rockville, MD: Agency for Healthcare Research and Quality; 2004. Available from: https://www.ncbi.nlm.nih.gov/ sites/books/NBK11852/

7. Patient-Centered Outcomes Research Institute (PCORI). Compensation Framework. https://www.pcori.org/document/compensation-framework. Accessed 8 November 2020.

8. Israel B, Eng E, Schulz A, Parker E, editors. Methods in community-based participatory research for health. San Francisco: Jossey-Bass; 2005

9. Minkler M, Wallerstein N. Community based participatory research for health: from process to outcomes. 2nd ed. San Francisco: Jossey bass; 2008.

10. Lefevre $P$, Kolsteren $P$, De Wael M, Byekwasco F, Beghin I. Comprehensive participatory planning evaluation. Antwerp: Belgium, IFAD/Belgian Survival Fund; 2000

11. Ndirangu M, Perkins H, Yadrick K, West J, Bogle M, Avis-Williams A, et al. Conducting needs assessment using the comprehensive participatory planning and evaluation model to develop nutrition and physical activity interventions in a rural community in the Mississippi Delta. Prog Community Health Partnersh. 2007;1(1):41-8. https:/doi.org/10.1353/cpr.0.0005.

12. Zoellner J, Motley M, Hill J, Wilkinson M, Jackman B, Barlow M. Engaging the Dan River region to reduce obesity: application of the comprehensive participatory planning and evaluation process. Fam Community Health. 2011;35(1):44-56. https://doi.org/10.1097/FCH.0b013e3182385cd9.

13. Hohman K, Given L, Farrell M, Barry A, Robertson L, Kerch S, et al. The nine habits of successful comprehensive cancer control coalitions. Cancer Causes Control. 2018;29(12):1195-203. https://doi.org/10.1007/s10552-018-1116-y.

14. Comprehensive Cancer Control National Partners. Updated nine habits of successful comprehensive cancer control coalitions. https://www.cccnationa Ipartners.org/updated-nine-habits-successful-comprehensive-cancer-controlcoalitions. Accessed 8 November 2020.

15. Wheeler SB, Davis MM. "Taking the bull by the horns": four principles to align public health, primary care, and community efforts to improve rural cancer control. J Rural Health. 2017;33(4):345-9. https://doi.org/10.1111/ jrh.12263.

16. Weaver SJ, Blake KD, Vanderpool RC, Gardner B, Croyle RT, Srinivasan S. Advancing rural cancer control research: National Cancer Institute efforts to identify gaps and opportunities. Cancer Epidemiol Biomark Prev. 2020;29(8): 1515-8. https://doi.org/10.1158/1055-9965.Epi-20-0453.

17. Blake KD, Moss JL, Gaysynsky A, Srinivasan S, Croyle RT. Making the case for investment in rural cancer control: an analysis of rural cancer incidence, mortality, and funding trends. Cancer Epidemiol Biomark Prev. 2017;26(7): 992-7. https://doi.org/10.1158/1055-9965.Epi-17-0092.

18. Hayes NS, Hohman K, Vinson C, Pratt-Chapman M. Comprehensive cancer control in the U.S.: summarizing twenty years of progress and looking ahead. Cancer Causes Control. 2018;29(12):1305-9. https://doi.org/10.1007/ s10552-018-1124-y.

19. Given LS, Coughlin R, Hager P, Lopez K, Merriam G, Morwood K, et al. Comprehensive cancer control in the US: 20 years of progress. Cancer Causes Control. 2018;29(12):1151-61. https://doi.org/10.1007/s10552-018-1 098-9.

20. Hohman K, Given L, Graaf L, Sergeant J, Muthukuda D, Devery T, et al. Evolution of comprehensive cancer control plans and partnerships. Cancer Causes Control. 2018;29(12):1181-93. https://doi.org/10.1007/s10552-01 8-1112-2.

21. Pyron T, Fonseka J, Young M, Zimmerman L, Moore AR, Hayes N. Examining comprehensive cancer control partnerships, plans, and program interventions: successes and lessons learned from a utilization-focused evaluation. Cancer Causes Control. 2018;29(12):1163-71. https://doi.org/10.1 007/s10552-018-1113-1.

22. Moore A, Villalobos A, Gardner AL, Staples C, Shafir S. Leveraging the strength of comprehensive cancer control coalitions to support policy, systems, and environmental change. Cancer Causes Control. 2019;30(10): 1033-44. https://doi.org/10.1007/s10552-019-01215-w.

23. Moy E, Garcia MC, Bastian B, Rossen LM, Ingram DD, Faul M, et al. Leading causes of death in nonmetropolitan and metropolitan areas- United States, 1999-2014. MMWR Surveill Summ. 2017;66(1):1-8. https://doi.org/10.15585/ mmwr.ss6601a1.
24. Singh GK, Williams SD, Siahpush M, Mulhollen A. Socioeconomic, rural-urban, and racial inequalities in US cancer mortality: part I-all cancers and lung cancer and part II-colorectal, prostate, breast, and cervical cancers. J Cancer Epidemiol. 2011;2011:107497-27. https://doi.org/10.1155/2011/107497.

25. Hill MS (2010) Addressing cancer burden in Appalachian communities. Appalachia Community Cancer Network.

26. Fisher JL, MCLaughlin JM, Katz ML, Wewers ME, Dignan MB, Paskett ED. Cancer-disparities. In: Ludke RL, Obermiller PJ, editors. Health and well-being in Appalachia. Lexington, KY: University of Kentucky Press; 2012.

27. Yao N, Alcala HE, Anderson R, Balkrishnan R. Cancer disparities in rural Appalachia: incidence, early detection, and survivorship. J Rural Health. 2016; 33(4):375-81. https://doi.org/10.1111/jrh.12213.

28. Mokdad AH, Dwyer-Lindgren L, Fitzmaurice C, Stubbs RW, Bertozzi-Villa A, Morozoff $C$, et al. Trends and patterns of disparities in cancer mortality among US counties, 1980-2014. JAMA. 2017:317(4):388-406. https://doi. org/10.1001/jama.2016.20324

29. Wilson RJ, Ryerson AB, Singh SD, King JB. Cancer incidence in Appalachia, 2004-2011. Cancer Epidemiol Biomark Prev. 2016;25(2):250-8. https://doi. org/10.1158/1055-9965.Epi-15-0946.

30. Camacho F, Hwang W, Kern T, Anderson RT. Receipt of regular primary care and early cancer detection in Appalachia. J Rural Health. 2015;31(3):269-81. https://doi.org/10.1111/jrh.12097.

31. Pollard K, Jacobsen $L$. The Appalachian region: a data overview from the 2013-2017 American community survey. Chartbook. Appalachian Regional Commission; 2019

32. Virginia Performs (2018) Health Risk Factors. http://vaperforms.virginia.gov/ indicators/healthFamily/healthRiskFactors.php. Accessed 2 January 2018.

33. Staniszewska S, Brett J, Simera I, Seers K, Mockford C, Goodlad S, et al. GRIP $\mathrm{P} 2$ reporting checklists: tools to improve reporting of patient and public involvement in research. BMJ. 2017:358.

34. Creswell J, Plano Clark V. Designing and conducting mixed methods research. 2nd ed. Thousand Oaks: SAGE Publications; 2011.

35. Zoellner J, Harris JE. Mixed-methods research in nutrition and dietetics. J Acad Nutr Diet. 2017;117(5):683-97. https://doi.org/10.1016/j.jand.2017.01.018.

36. Sandoval J, Lucero J, Oetzel J, Avila M, Belone L, Mau M, et al. Process and outcome constructs for evaluating community-based participatory research projects: a matrix of existing measures. Health Educ Res. 2012;27(4):680-90. https://doi.org/10.1093/her/cyr087.

37. University of Virginia School of Medicine. Cancer Center without Walls. https://med.virginia.edu/ccww/. Accessed 2 December 2019.

38. Oetzel JG, Zhou C, Duran B, Pearson C, Magarati M, Lucero J, et al. Establishing the psychometric properties of constructs in a communitybased participatory research conceptual model. Am J Health Promot. 2015; 29(5):e188-202. https://doi.org/10.4278/ajhp.130731-QUAN-398.

39. Marek LI, Brock D-JP, Savla J. Evaluating collaboration for effectiveness: conceptualization and measurement. Am J Eval. 2015;36(1):67-85. https:// doi.org/10.1177/1098214014531068.

40. Hargreaves MB, Verbitsky-Savitz N, Coffee-Borden B, Perreras L, White $C R$, Pecora PJ, et al. Advancing the measurement of collective community capacity to address adverse childhood experiences and resilience. Child Youth Serv Rev. 2017;76:142-53. https://doi.org/10.1016/ j.childyouth.2017.02.021

41. Brock DP, Estabrooks PA, Hill $U$, Barlow ML, Alexander RC, Price BE, et al. Building and sustaining community capacity to address childhood obesity: a 3-year mixed-methods case study of a community-academic advisory board. Fam Community Health. 2019;42(1):62-79. https://doi.org/10.1097/ fch.0000000000000212.

42. Tashakkori A, Teddlie C. Sage handbook of mixed methods in social and behavioral research. 2nd ed. Thousand Oaks: Sage Publications; 2010. https://doi.org/10.4135/9781506335193.

43. Elo S, Kyngäs $\mathrm{H}$. The qualitative content analysis process. J Adv Nurs. 2008; 62(1):107-15. https://doi.org/10.1111/j.1365-2648.2007.04569.x.

44. Graneheim U, Lundman B. Qualitative content analysis in nursing research: concepts, procedures and measures to achieve trustworthiness. Nurse Educ Today. 2004;24(2):105-12. https://doi.org/1 0.1016/j.nedt.2003.10.001.

45. Miles MB, Huberman AM, Saldana J. Qualitative data analysis: a methods sourcebook. London: Sage; 2014

46. Birt L, Scott S, Cavers D, Campbell C, Walter F. Member checking: a tool to enhance trustworthiness or merely a nod to validation? Qual Health Res. 2016;26(13):1802-11. https://doi.org/10.1177/1049732316654870. 
47. Cancer Action Coalition of Virginia (CACV). Virginia Cancer Plan. http://ca ncercoalitionofvirginia.org/pages/cacv-annual-reports.php. Accessed 2 December 2019.

48. National Institutes of Health National Cancer Institute (NIH-NCI). EvidenceBased Cancer Control Programs (EBCCP). Transforming Research into Community and Clincial Practice. https://ebccp.cancercontrol.cancer.gov/ index.do. Accessed 2 December 2020.

49. Community Preventive Service Task Force. The Community Guide. https:// www.thecommunityguide.org/topic/cancer. Accessed on 19 November 2019.

50. American Cancer Society. Cancer Screening Guidelines. https://www.cancer. org/healthy/find-cancer-early/cancer-screening-guidelines.html. Accessed on 4 October 2020

51. Linnan L, Steckler A. Process evaluation for public health interventions and research: an overview. In: process evaluation for public health interventions and research, vol. 1. San Francisco: Jossey-bass; 2002. p. 1-23.

52. Salimi Y, Shahandeh K, Malekafzali H, Loori N, Kheiltash A, Jamshidi E, et al. Is community-based participatory research (CBPR) useful? A systematic review on papers in a decade. Int J Prev Med. 2012;3(6):386-93.

53. Muhammad M, Wallerstein N, Sussman AL, Avila M, Belone L, Duran B. Reflections on researcher identity and power: the impact of positionality on community based participatory research (CBPR) processes and outcomes. Crit Sociol. 2015;41 (7-8):1045-63. https://doi.org/10.1177/0896920513516025.

54. Nowell B, Foster-Fishman P. Examining multi-sector community collaboratives as vehicles for building organizational capacity. Am J Community Psychol. 2011:48(3):193-207. https://doi.org/10.1007/s10464-01 0-9364-3.

55. Zoellner J, Porter K, Thatcher E, Kennedy E, Werth JL Jr, Grossman B, et al. A multilevel approach to understand the context and potential solutions for low colorectal cancer (CRC) screening rates in rural Appalachia clinics. J Rural Health. 2020. https://doi.org/10.1111/jrh.12522.

56. Garcia C, Lothamer H, Mitchell EM. Provider-identified barriers to cervical cancer screening and perceptions toward self-collection of human papillomavirus in Southwest Virginia. Public Health Nurs. 2016;33(6):539-46. https://doi.org/10.1111/phn.12285.

57. Mitchell EM, Lothamer H, Garcia C, Marais AD, Camacho F, Poulter M, et al. Acceptability and feasibility of community-based, lay navigator-facilitated athome self-collection for human papillomavirus testing in underscreened women. J Womens Health. 2020;29(4):596-602. https://doi.org/10.1089/jwh.2 018.7575.

58. Palafox NA, Given L, Hohman K, Taitano JR, Hedson J, Buenconsejo-Lum LE, et al. Comprehensive cancer control planning in the Pacific: the Cancer Council of the Pacific Islands a multi-national regional coalition. Cancer Causes Control. 2018;29(12):1287-95. https://doi.org/10.1007/s10552-018-1115-z.

59. Glasgow RE, Lichtenstein E, Marcus A. Why don't we see more translation of health promotion reseach to practice? Rethinking the efficacy-toeffectivenss transition. Am J Public Health. 2003;93(8):1261-7. https://doi. org/10.2105/AJPH.93.8.1261.

60. Boatman D, Eason S, Conn M, Miller S, Kennedy-Rea S. Advancing cancer prevention practice facilitation work in rural primary care during COVID-19. J Appalach Health. 2020;2(4):4-10.

61. Love B, Benedict C, Van Kirk VA, Cone JN. Communication and comprehensive cancer control coalitions: lessons from two decades of campaigns, outreach, and training. Cancer Causes Control. 2018;29(12): 1239-47. https://doi.org/10.1007/s10552-018-1122-0.

62. Ramanadhan S, Davis MM, Armstrong R, Baquero B, Ko LK, Leng JC, et al. Participatory implementation science to increase the impact of evidencebased cancer prevention and control. Cancer Causes Control. 2018;29(3): 363-9. https://doi.org/10.1007/s10552-018-1008-1.

63. Rochester PW, Townsend JS, Given L, Krebill H, Balderrama S, Vinson C. Comprehensive cancer control: progress and accomplishments. Cancer Causes Control. 2010;21(12):1967-77. https://doi.org/10.1007/s10552-0109657-8

\section{Publisher's Note}

Springer Nature remains neutral with regard to jurisdictional claims in published maps and institutional affiliations.

\section{Ready to submit your research? Choose BMC and benefit from:}

- fast, convenient online submission

- thorough peer review by experienced researchers in your field

- rapid publication on acceptance

- support for research data, including large and complex data types

- gold Open Access which fosters wider collaboration and increased citations

- maximum visibility for your research: over $100 \mathrm{M}$ website views per year

At $\mathrm{BMC}$, research is always in progress.

Learn more biomedcentral.com/submissions 